\title{
Herbal Medicine in America
}

\author{
Varro E. Tyler ${ }^{1}$ \\ Received: September 19, 1986
}

\begin{abstract}
Herbs and herbal products are relatively big business in America, but they are not commonly sold in pharmacies. Current federal laws do not permit the sale of herbs as drugs, that is, with claims of efficacy appearing on their labels. If such claims are made, the efficacy must be proven to the satisfaction of the Federal Food and Drug Administration, a process as much as $\$ 100$ million per drug. Since no one is willing to spend this amount of money on a product for which patent protection is not available, herbs are sold labeled only with the name of the product, primarily in "health food" stores. Literature purporting to explain the uses of the herbs is also available in such establishments. Most often it is outdated, not scientifically of clinically accurate, and is written primarily to promote the sale of the products.

Because the laws and regulations applied to foods naturally do not require any proof of efficacy prior to sale, some manufacturers attempt to market herbal products as nutrients, food supplements, nutritional products, or just plain foods. Another promotional scheme ist to combine minute of a variety of herbs with standard multivitamin-mineral preparations and then make extravagant claims for the products based on their herbal contents. Quality control in the American herb industry is, in general, very poor. Contamination or misidentification of herbs is commonplace, and herbs shown to be toxic in animal tests continue to be sold without restraint.

Although phytochemistry is not neglected in America, little attention is currently paid to the physiological or clinical utility of herbs. For financial reasons, serios studies of herbs will probably never be carried out in significant numbers there. This leaves just that much more to do in the herbal field for European scientists.
\end{abstract}

Before beginning our discussion of herbal medicine in America, perhaps it would be well to define the word herb as I intend to use it. This is especially necessary because herb is currently defined in so many different ways by different people. As employed in this presentation, herbs are crude vegetable drugs or their extracts that are utilized, primarily by lay persons, for the treatment of disease states, often of a chronic nature, or to attain or to maintain a state of improved health. The key words in this statement may be paraphrased as: crude vegetable drugs or extracts - selected and used by nonprofessionals - to cure disease or to maintain health.

To understand the status of herbal medicine in America today, one must have some knowledge of the basic laws relating to the sale of drugs here (1). The first significant federal (i.e., nationwide) regulation of pharmaceuticals came about as a result of the Food and Drug Act of 1906. Basically, it was a bold step to control fraud, especially in the proprietary drug or "patent-medicine" industry. Then, in 1938, the Federal Food,

\footnotetext{
${ }^{1}$ School of Pharmacy and Pharmacal Sciences, Pharmacy Building, Purdue University, West Lafayette, Indiana 47907, U.S.A.
}

Drug, and Cosmetic Act was passed: It required that all drugs sold be proven safe. This law was subsequently amended in 1962 to require that all drugs sold after that date be proven both safe and effective.

However, not all drugs were regulated by the 1938 law and the subsequent 1962 amendment. Drugs that had been on the market prior to 1938 were still covered by the original legislation which permitted their sale. Even if they were later proven ineffective, they could apparently not be removed from the market. In effect, they were "grandfathered" under the old law, and the newer regulations did not apply. Of course, most plant drugs or herbs fell in this category.

Still, the Federal Food and Drug Administration was not without resources. They simply declared that such a drug would be considered misbranded if any claim of efficacy was made on its label that was not satisfactorily proven (2). If such a claim were to be made, the drug could be confiscated. Incidentally, the label is broadly interpreted as meaning not only the words printed on the container or package but any accompanying literature (package insert) as well.

What happened next was very predictable. Reputable drug manufacturers were, in general, unwilling to spend the 50 to 100 million dollars required to prove that an ancient herb was an effective drug. Even if they could prove it, they could not be afforded any patent protection on it and would thus be unable to recover their investment readily. So, they simply stopped marketing these herbal drugs.

As a result, most plant drugs left the pharmacies where they had previously been sold by knowledgeable professionals. They migrated to the shelves of the "health food" stores where they are sold under the guise of herbs, teas, health foods, food supplements, nutritional products, etc., labeled only with the name of the product (3). And most of the time the name is a common one, often subject to several interpretations as to the exact botanical species it represents. No claim of effectiveness for any condition appears on the label of such containers nor in any leaflet or advertisement that directly accompanies the drug.

How then do the consumers learn of the uses and recommended doses of the various herbs? Often they do not. But generally, such stores have available a vast assortment of literature - books, pamphlets, and charts - which list the drugs and describe their supposed uses. These references range all the way from complete reprints of such extensive (and outdated) references as Nicholas Culpeper's herbal to small pamphlets covering a single herb or a single therapeutic class of remedies. Since this literature does not directly accompany a product, it is not considered part of any label, and therefore no charge of misbranding nor subsequent confiscation of the product occurs. 
Herbs and the literature about them are big business in America. In 1985 the sales of all forms of herbs exceeded $\$ 190$ million, and literature sales accounted for an additional $\$ 33$ million (4). Unfortunately, most of the literature is prepared with a single purpose in mind - to sell a product. Since to do so most effectively it is necessary to promote or advocate all of the good features of the herb while minimizing, or even omitting, any negative aspects, such writings are generally referred to as advocacy literature. Purposely, or perhaps through ignorance, the usually outdated information is presented in a completely uncritical fashion. In this way, the carcinogenic root bark of sassafras [Sassafras albidum (Nutt.) Nees] becomes a healthful tonic, the innocuous burdock root [Arctium lappa $\mathrm{L}$. or $A$. minus (Hill) Bernh.] continues to be recommended for hydrophobia, and the very toxic poke root (Phytolacca americana L.) is touted as an effective treatment for arthritis and rheumatism. A 42-year-old Wisconsin woman drank one cup of tea prepared from a half teaspoonful of poke root and required 24 hours of intensive hospital treatment before her condition stabilized (5).

Serious consequences do, therefore, arise from the use by uninformed consumers of herbs that bear no indication of their physiological effects on the label. Three Pennsylvania women developed severe abdominal pain and watery diarrhea three hours after drinking 1-2 cups each of an herbal tea. The illness lasted 24 hours. Each of the three lost one day of work and each sought medical assistance. The tea was subsequently found to consist of senna leaves (Cassia spp.), but, of course, there was nothing on the label to indicate that senna is a cathartic (6).

Because foods do not require any proof of efficacy prior to marketing and because the dividing line between foods and drugs is often a hazy one, some distributors of herbal remedies have attempted to circumvent the federal requirements by marketing their products as foods. The classic example of this strategy was the so-called starch blockers or, more technically, the alpha-amylase inhibitors. These consisted of proteins capable of interacting with alpha-amylase to form insoluble, inactive complexes. In theory, this would result in a net reduction of starch breakdown, thereby allowing undigested starch to pass through the gastrointestinal tract and rendering its caloric content physiologically unavailable. Starch blockers were therefore promoted as products useful in effecting weight loss. Since the inhibitors were usually obtained from white kidney beans (Phaseolus vulgaris L. Cv. Great Northern), they were said to be foods, not drugs.

Starch blockers were advertised by their producers as "a revolutionary new way to lose weight." One $550 \mathrm{mg}$ tablet was said to "block the digestion and absorption of $150 \mathrm{~g}$ of starch, which represents 600 calories." No new drug application (NDA), the first step in obtaining federal approval to market the product as a drug, was ever filed. Of course, the Food and Drug Administration reacted by declaring that the kidney bean extracts were actually drugs and that, under the law, premarketing approval had to be obtained before the product could be sold.

How did the 263 starch-blocker manufacturers and distributors react to this ruling? Did they pool their resources and attempt to produce scientific and clinical evidence for the safety and efficacy of a product for which such claims were being made to the public? They did not! Instead, they filed a lawsuit claiming that starch blockers were foods, not drugs, and were therefore exempt from regulation. A federal court in Illinois heard the case and ultimately ruled that, in spite of their natural origin from kidney beans, starch blockers were indeed drugs on the basis of the pharmacologic claims made for them by their manufacturers (7). This decision was not appealed, and starch blockers were withdrawn from the market.

Subsequent studies have now revealed what the producers of these products probably knew from the beginning; namely, starch blockers are not only ineffective but may produce considerable gastrointestinal discomfort in the form of diarrhea, flatulence, nausea, and abdominal pain (8). The dream of eating all the pasta, bread, cake, and potatoes one desired and then taking one little pill to avoid gaining weight remains just that - a dream.

Another promotional device employed by American herb distributors involves the incorporation of extremely minute quantities of a very large number of different plant materials into an otherwise standard multivitamin-mineral preparation and then making extravagant claims for the product based on its wonderful herbal content. After all, the advocacy literature makes such glowing claims regarding the utility of herbs that the American public has come to consider them as having almost magical properties.

One such product presently marketed in the United States is claimed to be a "miracle worker - a special blend of 14 herbs that are designed to naturally cleanse the digestive system and naturally help curb the appetite." As a result of legal action brought by governmental authorities, it became possible for me to examine the actual formulation sheets of this weight-loss product. Only two of the 14 herbs were present in quantities that might exert a weak physiological effect, at least in sensitive individuals (9). Both were laxatives. Senna leaves (Cassia ssp.) were present in amounts representing about $1 / 20$ th of the recommended daily dose; cascara sagrada (Rhamnus purshiana DC.) was contained in amounts equaling about $1 / 8$ th of the usual daily dose. Small amounts of kelp (species of Fucales and Laminariales) and dandelion root (Taraxacum officinale Web.) could possibly add to the slight laxative effect of the preparation, but the milligram quantities of the other herbs present would be totally ineffective. They were apparently added to the product only for the mystique that would be conferred by their exotic (to the layman) names.

Thus far, I have portrayed a rather dismal picture of the herbal medicine industry in America, and the negative aspects of the business have not yet been completely examined. The quality-control of herbs is extremely poor. In 1978 and 1979, two studies of 54 ginseng products noted that $60 \%$ of them contained so little ginseng that they were viewed as worthless, and $25 \%$ of the sampled products contained no ginseng at all (10, 11). There is no reason to believe that situation is any different today.

In 1983, one of the nation's largest suppliers of herbal products had to recall all of its comfrey tea because it was found to be contaminated with deadly nightshade (Atropa belladonna L.). A Mississippi woman nearly died after drinking a quantity of the contaminated product (12). And, speaking of comfrey (Symphytum spp.), one must wonder how it is that any responsible firm could even sell that herb, since it has been found to contain varying amounts of carcinogenic pyrrolizidine alkaloids. Yet, both comfrey root and leaf continue to be sold in every "health food" store and by every herb distributor in America. Other carcinogens, including coltsfoot (Tussilago farfara L.) and sassafras [Sassafras albidum (Nutt.) Nees], also continue to be widely sold, in spite of a long-standing government ban on the constituents of the latter herb.

Fortunately, there are some hopeful signs that this extremely negative situation in the field of herbal medicine will not be allowed to continue indefinitely. Here and there a few crusaders 
have taken up the challenge, and although their voices are still relatively feeble, they have begun to be heard. Several consumer-oriented groups, such as the National Council Against Health Fraud and the American Council on Science and Health, have begun to inform the public about the true utility of herbs. Several popular monthly newsletters, such as Nutrition Forum and Tufts University Diet and Nutrition Letter, have begun to feature articles disclosing the real facts about herbal products. It is significant to note, however, that these publications have as their primary focus the field of nutrition, not pharmacy or medicine. Many journals and newsletters in these latter two areas still disdain authoritative articles dealing with herbs and their uses.

Consumer Reports, an extremely influential, nationally circulated magazine devoted to examining product quality, has recently featured exposes of malpractice in the herbal field. And a very hopeful sign is the recent editorial reorientation of Prevention, a popular health magazine with 2.75 million circulation, toward a more conservative stance with regard to claims of utility for herbal products.

I, too, made a modest contribution to herbal accuracy in 1982 when I wrote The Honest Herbal, a 263-page book intended for the lay reader that critically examines the scientific and clinical evidence regarding the efficacy and safety of more than 100 of the most common herbs sold in America. Although the volume was critically acclaimed as "the best herb book ever!" it has not become a best seller because herbal sales people view it as being too conservative and thus refuse to handle it in their stores. Nevertheless, it has sold quite steadily ever since it was first published, and a paperback edition of The Honest Herbal is now scheduled to appear next year. It remains the only book of its type in America - that is, one providing accurate information, of both a positive and negative nature, on the efficacy and safety of herbs.

Although I would make no claim to having a thorough familiarity with books on herbs in languages other than English, I do have a considerable knowledge of such books in, particularly, German and in French as well. I must say that, in general, these volumes are quite disappointing. The work by Maria Treben is as uncritical as the worst herbal advocacy literature in America, and even some volumes purporting to be critical fail to present the complete picture. The best such European book, in my opinion, is Therapie mit Phytopharmaka by $\mathrm{R}$. Hänsel and $\mathrm{H}$. Haas. Of course, it is not exactly an herbal in the classical meaning of the term.

Another encouraging development in the herbal field is currently taking place in Canada. Since that nation is certainly part of America, it is appropriate to discuss the matter here. An Expert Advisory Committee on Herbs and Botanical Preparations has issued a report containing several significant recommendations (13). The most important of these would establish a new class of drugs designated "Folklore Medicines." These would include herbal remedies demonstrated to be safe, but the efficacy of which was not necessarily proven by standard methods applicable to other drugs. Instead, it would be supported by folkloric claims. Such products would have to be appropriately labeled, and standards of quality would be established and maintained.

It seems to me that this proposal is a most sensible one, and if it is ultimately adopted in Canada, should provide a real stimulus to the development of the field of herbal medicine. It precludes the necessity of spending scores of millions of dollars on the clinical testing of well-known remedies with little hope of ever recovering that investment. Those interested in herbs should follow the implementation of the proposals in this report with considerable interest.

However, on a less optimistic note, I must add that I discussed the essence of the Canadian proposals with a former Commissioner of the Food and Drug Administration in the United States. He expressed the belief that creation of a special class of herbal drugs, marketed without absolute clinical proof of efficacy, would not be feasible here. Product liability laws and the litigious climate in the United States would probably preclude enactment of such a scheme, in spite of its many attractive features.

Thus, the overall outlook for herbal medicine in America is not bright, in spite of the enormous interest in the field by nonprofessionals. Basically, it appears that the unsatisfactory status quo will continue indefinitely. Herbs will continue to be sold by nonprofessional persons in nondrug outlets to uninformed or misinformed consumers who will probably use them improperly for conditions that the herbs will not benefit. It is a very discouraging situation, particularly when one realizes that, if properly used by knowledgeable people, some of the herbs could make a real contribution to health maintenance and to the cure of disease.

Perhaps most disappointing to Americans like me is the prospect that most developments in the field of herbal medicine will, of necessity, come from other countries. A recent example in Britain is the use of feverfew [Chrysanthemum parthenium (L.) Bernh.] in the treatment of migraine and arthritis $(14,15)$. A number of publications dealing with this interesting herb and its promising potential have appeared in Britain during recent years, but these have gone unnoticed in the United States, at least as far as scientific interests are concerned.

Another development of interest is the use, in Germany, of Echinacea preparations [Echinacea angustifolia DC. and $E$. purpurea (L.) Moench] to stimulate the immune system and increase resistance to disease (16). Although large quantities of these roots are currently grown and harvested in the United States and shipped to Europe where preparations of them are widely marketed, the herb remains little used, indeed practically unknown, in America.

That is not to say that new chemical entities from plants will be neglected in America. Phytochemistry is still fairly vigorous in this country, but even in that field far too little attention is being paid to the physiological activity and, especially, the clinical utility of natural drug products. As far as the investigation of crude vegetable drugs, that is, herbs, is concerned, serious studies will probably never be carried out in any significant number in America unless existing laws and regulations are modified.

I regret having to conclude on this pessimistic note. However, as Europeans, you should be able to see the significance of all this for yourselves. If Americans are to continue to neglect the field of herbal medicine, there is just that much more for you to do. I encourage you to meet that challenge.

\section{References}

(1) Ziporyn, T. (1985) J. Am. Med. Assoc. 254, 2037.

(2) Harlow, D. R. (1977) Food Drug Cosmet. Law J. 32, 248.

(3) Tyler, V. E. (1982) The Honest Herbal, p. 16, George F. Stickley Company, Philadelphia.

(4) Anon. (1986) Health Foods Bus. 32 (3), 42.

(5) Anon. (1979) Whole Foods 2 (4), 14.

(6) Anon. (1978) MMWR 27, 249. 
(7) Rosenberg, I. H. (1982) New Engl. J. Med. 307, 1444.

(8) Liberti, L. E. (1985) Lawrence Rev. Nat. Prod. 6, 37.

(9) Fanning, O. (1985) Nutr. Forum 2, 66.

(10) Liberti, L. E., Der Marderosian, A. (1978) J. Pharm. Sci, 67, 1487.

(11) Ziglar, W. (1979) Whole Foods 2 (4), 48.

(12) Anon. (1983) Indianapolis Star Nov. 14, 4.

(13) Report of the Expert Advisory Committee on Herbs and Botani- cal Preparations (1986), Minister of National Health and Welfare, Canada, p. 9.

(14) Heptinstall, S., White, A., Williamson, L., Mitchell, J. R. A. (1985) Lancet I, 1071.

(15) Johnson, E. S., Kadam, N. P., Hylands, D. M., Hylands, P. J. (1985) Br. Med. J. 291, 569.

(16) Becker, H. (1982) Dtsch. Apoth. Ztg. 122, 2320. 